\title{
Mathematical Modeling of a Supply Chain with Imperfect Transport and Two-Echelon Trade Credits
}

\author{
A. Thangam \\ Department of Computer Science and Mathematics, Pondicherry University Community College, Pondicherry 605 008, India \\ Correspondence should be addressed to A. Thangam; thangamgri@yahoo.com
}

Received 25 February 2013; Accepted 21 March 2013

Academic Editors: M. Fakhar and Y. Kara

Copyright (c) 2013 A. Thangam. This is an open access article distributed under the Creative Commons Attribution License, which permits unrestricted use, distribution, and reproduction in any medium, provided the original work is properly cited.

\begin{abstract}
Although a smoothly running supply chain is ideal, the reality is to deal with imperfectness in transportations. This paper tries to propose a mathematical model for a supply chain under the effect of unexpected disruptions in transport. Supplier offers the retailer a trade credit period $t_{1}$ and the retailer in turn offers his customers a permissible delay period. The retailer offers his customers a credit period $t_{2}$ and he receives the revenue from $t_{2}$ to $T+t_{2}$, where $T$ is the cycle time at the retailer. Under this situation, the three cases such as $T \leq t_{1} \leq T+t_{2}, T \leq T+t_{1} \leq t_{2}$, and $t_{1} \leq t_{2}$ are discussed. An EPQ-based model is established and retailer's optimal replenishment policy is obtained through mathematical theorems. Finally, numerical examples and sensitivity analysis are presented to felicitate the proposed model.
\end{abstract}

\section{Introduction}

Much of the logistician's planning and control effort is directed toward running an efficient operation under normal conditions. At the same time, global trades such as Wal-Mart, Home Depot, and Dollar General are facing the extraordinary circumstances (such as earth quake, mishandling in transport, shipping damage, and misplacing products) that may result a risk in delivery from a supplier to a retailer. The supply disruptions take the form of high-impact and low-probability contingencies which can threaten decision makers of a supply chain. Mathematical modeling helps decision makers to evaluate optimal ordering policies against an incredibly complex and dynamic set of risks and constraints.

In the classical logistics models, it was assumed that the retailers and their customers must pay for the items as soon as the items are received. However, in practices, the supplier/retailer would allow a specified credit period (say 30 days) to their retailers/customers for payment without penalty to stimulate the demand of the consumable products. This credit term in financial management is denoted as "net 30." Teng [1] illustrated the benefits of trade credit policy: (1) it attracts new customers who consider trade credit policy to be a type of price reduction, and (2) it should cause a reduction in sales outstanding, since some established customer will pay more promptly in order to take advantage of trade credit more frequently.

This paper investigates a supply chain model in which the supplier is willing to provide the retailer a full trade credit period for payments and the retailer offers the full trade credit to his/her customer. This is called two-echelon (or two-level) trade credit financing. In practice, this two-level trade credit financing at a retailer is more matched to real-life situations in a supply chain. Companies, like TATA and Toyato, can delay the full amount of purchasing cost until the end of the delay period offered by his suppliers. But these companies only offer partial delay payment to his dealership on the permissible credit period.

This paper attempts to develop a mathematical model for the supply chain with two-level trade credits and probabilistic considerations of supply disruptions. To manage the risk in delivery, the retailer arranges some alternatives to rework those defective items which involve defective costs. Here, the retailer offers trade credits to his customers and also receives full trade credit from the supplier. The retailer replenishes his inventory noninstantaneously and faces probabilistic risks due to supply disruptions. According to risk management in operations research, two situations such as (a) risk neutral and (b) risk averse are considered. The solution procedures are described for the retailer in both cases. 
The rest of this paper is organized as follows. The literature review is presented in Section 2. Notations and assumptions are described in Section 3. In Section 4, a mathematical model for the illustrated supply chain is developed. Optimal solutions are obtained in Section 5. Numerical examples are illustrated in Section 6 and conclusions are drawn in Section 7.

\section{Literature Review}

During the past few years, many researchers have studied inventory models for permissible delay in payments. Goyal [2] was the first proponent for developing an economic order quantity (EOQ) model under the conditions of permissible delay in payments. Shah [3] considered a stochastic inventory model when items in inventory deteriorate and delays in payments are permissible. Aggarwal and Jaggi [4] extended Goyal's model to allow for deteriorating items. Jamal et al. [5] further generalized Aggarwal and Jaggi's model to allow for shortages. Hwang and Shinn [6] developed a model considering exponentially deteriorating items and found decision policy for selling price and lot size. Teng [1] amended Goyal's model by considering the difference between unit price and unit cost and established an easy analytical closed-form solution to the problem. Chung and Huang [7] generalized Goyal's EOQ model to an economic production quantity (EPQ) model in which the selling price is the same as the purchase cost. Huang [8] extended Goyal's model to the case in which the supplier offers the retailer the permissible delay period $M$ (i.e., the upstream trade credit) and the retailer in turn provides the trade credit period $N$ (with $N<M$ ) to his customers (i.e., the downstream trade credit). Teng and Goyal [9] amended Huang's model by complementing his shortcomings. Chang et al. [10] reviewed the contributions on the literature in modeling inventory lot sizing under trade credits. Ho et al. [11] developed an integrated supplierbuyer inventory model with the assumption that demand is sensitive to retail price and the supplier adopts a twopart trade credit policy. Huang and Hsu [12] have developed an inventory model under two-level trade credit policy by incorporating partial trade credit option at the customers of the retailer. Liao [13] developed an EOQ model with noninstantaneous receipt and exponentially deteriorating items under two-level trade credit financing. Teng and Chang [14] extended the Huang [15] model by relaxing the assumption $N<M$. Jaggi et al. [16] developed a simple EOQ model in which the retailer's demand is linked to credit period. Thangam and Uthayakumar [17] developed an EPQ model for perishable items under two-level trade credit policy and selling price and credit-period-dependent demand. Teng [18] developed an EOQ model for a retailer who receives a full trade credit from his supplier and offers a partial trade credit to his bad credit customers or a full trade credit to his good credit customers. Tsao [19] developed a model by considering advance sales discount and trade credits. Chen and Kang [21] considered trade credit and imperfect quality in an integrated vendor-buyer supply chain model. Chen and Kang [20] developed integrated vendor-buyer inventory model with two-level trade credits and price negotiation scheme.
Chang et al. [22] have extended the Liao [13] model by considering the case $M<N$ also. Balkhi [23] has developed a finite horizon inventory model with deteriorating items under inflation and time value of money when shortages are not allowed. Liao et al. [24] have developed a two-warehouse lot-sizing model with order-dependent trade credit period. Tsao and Sheen [25] have developed a multi-item supply chain model with trade credit periods and weight freight cost. Thangam and Uthayakumar [26] have built a mathematical model for a retailer under two-level trade credit and twopayment methods. Recently, Thangam [27] has developed a two-level trade credit financing model for a supply chain with deteriorating items and advance payment scheme.

For the literature related to supply disruptions, Gulyani [28] studied the effects of highly ineffective freight transportation systems on the supply chain and showed how it increases the probability of incurring damage in transit and total inventories. Silver [29] used the EOQ model illustrating a situation where the order quantity received from the supplier does not necessarily match the quantity requisitioned. He showed that the optimal order quantity depends on the mean and standard deviation of the amount received. Shih [30] developed optimal ordering schemes in cases where the proportion of defective products in the accepted lots has a known probability distribution. Noori and Keller [31] extended Silver's [29] model and obtained optimal replenishment policy when the amount of products received at stores assumes probability distributions such as uniform, normal, and gamma. Blos et al. [32] identified supply chain risks in the automotive and electronic industries in Brazil and highlighted the urgency of supply chain risk in management implementation. Tsao [33] has developed an EPQ inventory model with trade credit and logistics risk in a one-level trade credit financing.

\section{Notations and Assumptions}

$\lambda$ : Annual demand rate at the retailer

$P$ : Replenishment rate at the retailer, $P \geq \lambda$

c: Unit purchasing cost

$s$ : Unit selling price, $s \geq c$

$A$ : The ordering cost per order

$h$ : Stock holding cost per year excluding interest charge

$I_{k}$ : The interest charged per dollar in stock per year

$I_{e}$ : The interest earned per dollar per year

$t_{1}$ : The retailer's trade credit period offered by the supplier in years

$t_{2}$ : The customer's trade credit period offered by the retailer in years

$\pi$ : Defective cost, the unit cost per item due to defectiveness in disruption intransport

$x$ : Percentage of imperfect quality products due to disruption in transport

$t_{c}$ : Time when contingency occurs 
$\mathrm{TC}(T)$ : The annual total cost incurred at the retailer, which is a function of $T$.

This paper considers the following assumptions.

(1) The present model is confined to single supplier, single retailer, and multiple customers.

(2) The inventory system deals with only one type of item.

(3) Shortages are not allowed.

(4) Demand rate $(\lambda)$ and replenishment rate $(R)$ are known and are constant.

(5) Lead time is zero.

(6) Time period is infinite.

(7) The supplier offers the full trade credit $t_{1}$ to the retailer.

(8) The retailer also offers the trade credit $t_{2}$ to his customers.

(9) Elapsed time $\left(t_{c}\right)$ until contingency occurs is a probabilistic continuous random variable. According to birth-death process in queueing theory, $t_{c}$ follows an exponential distribution with mean $1 / \mu$.

(10) If the products are defective due to contingency in delivery, the retailers need to find supply sources to recover these defective products. It accounts for the defective cost $\pi$.

\section{Mathematical Model Formulation}

The objective is to minimize the annual total cost incurred at the retailer:

\section{TC $(T)$}

$=$ Annual ordering cost + Annual stock holding cost

+ Annual interest payable - Annual interest earned

+ Annual defective cost.

(1) Annual ordering cost $=A / T$.

(2) Excluding interest charges, the annual stock holding cost is

$$
\frac{h T(P-\lambda)(\lambda T / P)}{2 T}=\frac{h}{2}\left[\lambda\left(1-\frac{\lambda}{P}\right)\right] T .
$$

(3) Interest earned by the retailer.

Case $1\left(T \leq t_{1} \leq T+t_{2}\right)$. Consider the following:

$$
\begin{aligned}
\text { Annual interest earned } & =\frac{s I_{e}}{T}\left[\frac{\lambda\left(t_{1}-t_{2}\right)^{2}}{2}\right] \\
& =\frac{s I_{e} \lambda}{2 T}\left(t_{1}-t_{2}\right)^{2} .
\end{aligned}
$$

Case $2\left(T \leq T+t_{1} \leq t_{2}\right)$. Consider the following:

Annual interest earned $=\frac{s I_{e}}{2 T}\left[\frac{\lambda T^{2}}{2}+\lambda T\left(t_{1}-t_{2}-T\right)\right]$.

Case $3\left(t_{1} \leq t_{2}\right)$. There is no interest earned for the retailer since retailer's credit period is prior to customer's credit period.

(4) Interest payable by the retailer.

Case $1\left(T \leq t_{1} \leq T+t_{2}\right)$. Consider the following:

$$
\text { Interest payable }=\frac{c I_{k}}{T}\left[\frac{\lambda\left(T+t_{2}-t_{1}\right)^{2}}{2}\right]
$$

Case $2\left(T \leq T+t_{1} \leq t_{2}\right)$. There is no interest payable for the retailer.

Case $3\left(t_{1} \leq t_{2}\right)$. Consider the following:

$$
\text { Interest payable }=\frac{c I_{k}}{T}\left[\left(t_{1}-t_{2}\right) \lambda T+\frac{\lambda T^{2}}{2}\right] .
$$

(5) Annual defective cost due to disruption in supply.

If the number of defective items in each replenishment cycle, as in Tsao [33], is

$$
\gamma= \begin{cases}0 & \text { if } t_{c} \geq \frac{\lambda T}{P} \\ x P\left(\frac{\lambda T}{P}-t_{c}\right) & \text { if } t_{c}<\frac{\lambda T}{P}\end{cases}
$$

then the expected number of defective products in each cycle is

$$
\begin{aligned}
E[\gamma] & =\int_{0}^{\infty} \gamma \mu e^{-\mu t_{c}} d t_{c} \\
& =P x\left[\frac{\lambda T}{P}+\frac{1}{\mu}\left(e^{-\mu(\lambda T / P)}-1\right)\right] .
\end{aligned}
$$

The annual defective cost is

$$
\frac{\pi \lambda E[\gamma]}{P(\lambda T / P)}=\pi \lambda x\left(1+\frac{e^{-\mu(\lambda T / P)}-1}{P}\right) .
$$

Using the approximation $e^{-x} \approx 1-x+\left(x^{2} / 2\right)$, the annual defective cost can be rewritten as $(\pi \lambda x \mu / 2)(\lambda T / P)$ when $\mu$ is small.

Therefore, the total cost incurred at the retailer $\mathrm{TC}(T)$ is

$$
\mathrm{TC}(T)= \begin{cases}\mathrm{TC}_{1}(T) & \text { if } T \leq t_{1} \leq T+t_{2} \\ \mathrm{TC}_{2}(T) & \text { if } T \leq T+t_{1} \leq t_{2} \\ \mathrm{TC}_{3}(T) & \text { if } t_{1} \leq t_{2}\end{cases}
$$


where

$\mathrm{TC}_{1}(T)$

$$
\begin{aligned}
= & \frac{A}{2}+\frac{h}{2}\left[\lambda\left(1-\frac{\lambda}{P}\right)\right] T \\
& +\frac{c I_{k} \lambda}{2 T}\left[T^{2}+\left(t_{1}-t_{2}\right)^{2}+2 T\left(t_{1}-t_{2}\right)\right] \\
& -\frac{s I_{e} \lambda}{2 T}\left[\left(t_{1}-t_{2}\right)^{2}\right]+\frac{\pi \lambda x \mu}{2}\left(\frac{\lambda T}{P}\right),
\end{aligned}
$$

$\mathrm{TC}_{2}(T)$

$$
\begin{aligned}
= & \frac{A}{2}+\frac{h}{2}\left[\lambda\left(1-\frac{\lambda}{P}\right)\right] T \\
& -\frac{s I_{e} \lambda}{2 T}\left[\lambda T^{2}+2 \lambda T\left(t_{1}-t_{2}-T\right)\right] \\
& +\frac{\pi \lambda x \mu}{2}\left(\frac{\lambda T}{P}\right),
\end{aligned}
$$

$\mathrm{TC}_{3}(T)$

$$
\begin{aligned}
= & \frac{A}{2}+\frac{h}{2}\left[\lambda\left(1-\frac{\lambda}{P}\right)\right] T+\frac{c I_{k}}{T}\left[\lambda\left(t_{1}-t_{2}\right) T+\frac{\lambda T^{2}}{2}\right] \\
& +\frac{\pi \lambda x \mu}{2}\left(\frac{\lambda T}{P}\right) .
\end{aligned}
$$

\section{Optimal Solutions}

Here, two situations, namely, (a) risk neutral and (b) risk averse are considered. To minimize the annual total cost $\mathrm{TC}(T)$, the following cases are considered.

\subsection{Risk-Neutral Situation}

Case 1 (when $T \leq t_{1} \leq T+t_{2}$ ). The first-order and secondorder derivatives of $\mathrm{TC}_{1}(T)$ are as follows:

$$
\begin{aligned}
& \frac{d \mathrm{TC}_{1}(T)}{d T} \\
& =\frac{-1}{2 T^{2}}\left[2 A-c I_{k} \lambda\left[T^{2}-\left(t_{1}-t_{2}\right)^{2}\right]+s I_{e} \lambda\left(t_{1}-t_{2}\right)^{2}\right] \\
& \quad+\frac{h}{2} \lambda\left(1-\frac{\lambda}{P}\right)+\frac{\pi \lambda x \mu}{2}\left(\frac{\lambda}{P}\right) \\
& \quad \frac{d^{2} \mathrm{TC}_{1}(T)}{d T^{2}}=\frac{2 A}{T^{3}}-\left(s I_{e}-c I_{k}\right) \lambda \frac{\left(t_{1}-t_{2}\right)^{2}}{T^{3}} .
\end{aligned}
$$

If $\left[2 A-\left(s I_{e}-c I_{k}\right) \lambda\left(t_{1}-t_{2}\right)^{2}\right]>0$, then $\mathrm{TC}_{1}(T)$ is a convex function of $T$; therefore, there exists an optimal cycle time
$T_{1}^{*}$ which minimizes $\mathrm{TC}_{1}(T)$. Solving $\left(d \mathrm{TC}_{1}(T) / d T\right)=0$, the optimal replenishment cycle time is

$$
T_{1}^{*}=\sqrt{\frac{\left[2 A-\left(s I_{e}-c I_{k}\right) \lambda\left(t_{1}-t_{2}\right)^{2}\right]}{\lambda\left[h(1-(\lambda / P))+c I_{k}+\pi x \mu(\lambda / P)\right]}} .
$$

To ensure the condition that $\left(t_{1}-t_{2}\right) \leq T$, it is observed that

$$
\begin{aligned}
T^{*}= & T_{1}^{*} \text { if and only if } 2 A \geq \lambda\left(t_{1}-t_{2}\right)^{2} \\
& \times\left[h\left(1-\frac{\lambda}{P}\right)+s I_{e}+\pi \times \mu\left(\frac{\lambda}{P}\right)\right] .
\end{aligned}
$$

Case 2 (when $T \leq T+t_{1} \leq t_{2}$ ). The first-order and secondorder derivatives of $\mathrm{TC}_{2}(T)$ are as follows:

$$
\begin{aligned}
\frac{d \mathrm{TC}_{2}(T)}{d T} & =\frac{-A}{T^{2}}+\frac{h}{2} \lambda\left(1-\frac{\lambda}{P}\right)+\frac{s I_{e} \lambda}{2}+\frac{\pi \lambda x \mu}{2}\left(\frac{\lambda}{P}\right), \\
\frac{d^{2} \mathrm{TC}_{2}(T)}{d T^{2}} & =\frac{2 A}{T^{3}}>0 .
\end{aligned}
$$

Observing that the second derivative $\mathrm{TC}_{2}(T)$ is a convex function of $T$, therefore there exists an optimal cycle time $T_{2}^{*}$ which minimizes $\mathrm{TC}_{2}(T)$. Solving $\left(d \mathrm{TC}_{2}(T) / d T\right)=0$, the optimal replenishment cycle time is

$$
T_{2}^{*}=\sqrt{\frac{2 A}{\lambda\left[h(1-(\lambda / P))+s I_{e}+\pi x \mu(\lambda / P)\right]}} .
$$

Ensuring the condition that $\left(t_{1}-t_{2}\right) \geq T$, it is observed that

$$
\begin{aligned}
T^{*}= & T_{2}^{*} \text { if and only if } 2 A \leq \lambda\left(t_{1}-t_{2}\right)^{2} \\
& \times\left[h\left(1-\frac{\lambda}{P}\right)+s I_{e}+\pi x \mu\left(\frac{\lambda}{P}\right)\right] .
\end{aligned}
$$

Case 3 (when $t_{1} \leq t_{2}$ ). The first-order and second-order derivatives of $\mathrm{TC}_{3}(T)$ are as follows:

$$
\begin{aligned}
\frac{d \mathrm{TC}_{3}(T)}{d T} & =\frac{-A}{T^{2}}+\frac{h}{2} \lambda\left(1-\frac{\lambda}{P}\right)+\frac{c I_{k} \lambda}{2}+\frac{\pi \lambda x \mu}{2}\left(\frac{\lambda}{P}\right), \\
\frac{d^{2} \mathrm{TC}_{3}(T)}{d T^{2}} & =\frac{2 A}{T^{3}}>0 .
\end{aligned}
$$

Observing that the second derivative $\mathrm{TC}_{3}(T)$ is a convex function of $T$, therefore there exists an optimal cycle time $T_{3}^{*}$ which minimizes $\mathrm{TC}_{3}(T)$. Solving $\left(d \mathrm{TC}_{3}(T) / d T\right)=0$, the optimal replenishment cycle time is

$$
T_{3}^{*}=\sqrt{\frac{2 A}{\lambda\left[h(1-(\lambda / P))+c I_{k}+\pi x \mu(\lambda / P)\right]}} .
$$

From the previous discussions, the following theorem is obtained. 
Theorem 1. (1) When $t_{1} \geq t_{2}$, one has the following.

(a) If $2 A \geq \lambda\left(t_{1}-t_{2}\right)^{2}\left[h(1-(\lambda / P))+s I_{e}+\pi x \mu(\lambda / P)\right]$ then there exists an optimal replenishment cycle time $T_{1}^{*}$ as in (13).

(b) If $2 A \leq \lambda\left(t_{1}-t_{2}\right)^{2}\left[h(1-(\lambda / P))+s I_{e}+\pi x \mu(\lambda / P)\right]$ then there exists an optimal replenishment cycle time $T_{2}^{*}$ as in (16)

(2) When $t_{1} \geq t_{2}$, there exists an optimal replenishment cycle time $T_{3}^{*}$ as in (19).

5.2. Risk-Averse Solution. In this section, a solution procedure is given to find optimal replenishment policy by limiting the expected number of defective items (up to $D_{\max }$ ) due to supply disruptions in transport. Now, the optimization problem is

$$
\mathrm{TC}(T)= \begin{cases}\mathrm{TC}_{1}(T) & \text { if } T \leq t_{1} \leq T+t_{2} \\ \mathrm{TC}_{2}(T) & \text { if } T \leq T+t_{1} \leq t_{2} \\ \mathrm{TC}_{3}(T) & \text { if } t_{1} \leq t_{2}\end{cases}
$$

subject to

$$
E[\gamma] \leq D_{\max }
$$

Case 1 (when $T \leq t_{1} \leq T+t_{2}$ ). Kuhn-Tucker conditions are used to solve the constrained optimization as in (20). In this case, the following are the Kuhn-Tucker conditions:

$$
\begin{aligned}
& \frac{d \mathrm{TC}_{1}(T)}{d T} \\
&-\eta_{1} \frac{d}{d T}\left[E[\gamma]-D_{\max }\right]-\eta_{2} \frac{d}{d T}\left[\left(t_{1}-t_{2}\right)-T\right]=0 \\
& E[\gamma]-D_{\max } \leq 0 \\
& {\left[\left(t_{1}-t_{2}\right)-T\right] \leq 0 } \\
& \eta_{1}\left[E[\gamma]-D_{\max }\right]=0 \\
& \eta_{2}\left[\left(t_{1}-t_{2}\right)-T\right]=0 \\
& \eta_{1} \geq 0, \quad \eta_{2} \geq 0
\end{aligned}
$$

If $T_{1}^{*}$ is the optimal replenishment cycle time, then there exist values $\eta_{1}^{*}$ and $\eta_{2}^{*}$ such that $T_{1}^{*}, \eta_{1}^{*}$, and $\eta_{2}^{*}$ satisfy the previous conditions.

Case 2 (when $T \leq T+t_{1} \leq t_{2}$ ). In this case, the following are the Kuhn-Tucker conditions:

$$
\begin{aligned}
& \frac{d \mathrm{TC}_{2}(T)}{d T} \\
&-\eta_{1} \frac{d}{d T}\left[E[\gamma]-D_{\max }\right]-\eta_{2} \frac{d}{d T}\left[\left(T-t_{2}\right)+t_{1}\right]=0, \\
& E[\gamma]-D_{\max } \leq 0, \\
& {\left[\left(T-t_{2}\right)+t_{1}\right] \leq 0, }
\end{aligned}
$$

$$
\begin{gathered}
\eta_{1}\left[E[\gamma]-D_{\max }\right]=0, \\
\eta_{2}\left[\left(T-t_{2}\right)+t_{1}\right]=0, \\
\eta_{1} \geq 0, \quad \eta_{2} \geq 0 .
\end{gathered}
$$

If $T_{2}^{*}$ is the optimal replenishment cycle time, then there exist values $\eta_{1}^{*}$ and $\eta_{2}^{*}$ such that $T_{2}^{*}, \eta_{1}^{*}$, and $\eta_{2}^{*}$ satisfy the previous conditions.

Case 3 (when $t_{1} \leq t_{2}$ ). In this case, the following are the Kuhn-Tucker conditions:

$$
\begin{gathered}
\frac{d \mathrm{TC}_{3}(T)}{d T} \\
-\eta_{1} \frac{d}{d T}\left[E[\gamma]-D_{\max }\right]-\eta_{2} \frac{d}{d T}\left[t_{1}-t_{2}\right]=0 \\
E[\gamma]-D_{\max } \leq 0 \\
{\left[t_{1}-t_{2}\right] \leq 0} \\
\eta_{1}\left[E[\gamma]-D_{\max }\right]=0 \\
\eta_{2}\left[t_{1}-t_{2}\right]=0 \\
\eta_{1} \geq 0, \quad \eta_{2} \geq 0
\end{gathered}
$$

If $T_{3}^{*}$ is the optimal replenishment cycle time, then there exist values $\eta_{1}^{*}$ and $\eta_{2}^{*}$ such that $T_{3}^{*}, \eta_{1}^{*}$, and $\eta_{2}^{*}$ satisfy the previous conditions.

\section{Numerical Example}

In order to illustrate the model, we consider the following examples.

Let $P=1000, \lambda=500, A=80, s=15, c=10, \pi=6$, $x=0.4, \mu=0.1, h=7, I_{k}=0.1, I_{e}=0.2, M=0.1$, and $N=0.06$. For risk-neutral solution, applying Theorem 1 , we get $T_{2}^{*}=0.1109, \mathrm{TC}_{2}\left(T_{2}^{*}\right)=112.65$. The expected number of defective items $E[\gamma]=2.91$.

For the risk-averse solution, we limit the expected number of defective items at most $D_{\max }=1$. Using the solution procedure in Section 5.2, we obtain $T_{2}^{*}=0.2, \mathrm{TC}_{2}\left(T_{2}^{*}\right)=287$. The total cost in the risk-averse solution is greater than that in the risk-neutral solution. It is because that the retailer will increase the cost to reduce the product's defectiveness which is bound to be within the upper limit $D_{\max }$. If the number of defective items $D_{\max }=2$, the total cost in the risk-averse solution is 296.2; if the number of defective items $=3$, the total cost in the risk-averse case is 58.98. This means that when the number of defective products is larger than 3 , the risk-averse solution gives total cost lesser than that in the risk-neutral solution. On the contrary, when the number of defective items is less than or equal to 2, the risk-neutral solution is better than the risk-averse solution. In the case $\lambda=1000$, that is 100 units ( $1 / 10$ of the demand) defect, the total cost in risk-neutral solution is 98.83 , whereas the risk-averse solution is 26.41; this means that the risk-averse solution can save $98.83-26.41=62.42$ dollars. Therefore 
this method is useful for the case of low-probability highconsequence contingency event.

The previous examples illustrate that when the number of defective items is limited to 2 , the risk-neutral solution is better than the risk-averse solution; if number of defective items is greater than or equal to 3 , then the risk-averse solution is better than the risk-neutral one.

\section{Conclusions and Future Research}

The illustrated model is very useful for low-probability highconsequence contingency event. In this paper, an EPQ-based model in which retailer offers trade credit to his customer and fixes the bound for defectiveness due to contingency such as shipping damages, misplacing products, earthquake, and hurricane is developed. Theorem 1 has been established to determine optimal solutions under various conditions. Two solution procedures are discussed for both risk-neutral and risk-averse cases. Finally numerical examples have been given to illustrate theoretical results, and the sensitivity analysis of key model parameters has been examined.

For the future research, this paper can be extended by considering perishable items or seasonal products.

\section{References}

[1] J. T. Teng, "On the economic order quantity under conditions of permissible delay in payments," Journal of the Operational Research Society, vol. 53, no. 8, pp. 915-918, 2002.

[2] S. K. Goyal, "Economic order quantity under conditions of permissible delay in payments," Journal of the Operational Research Society, vol. 36, no. 4, pp. 335-338, 1985.

[3] N. H. Shah, "Probabilistic time-scheduling model for an exponentially decaying inventory when delays in payments are permissible," International Journal of Production Economics, vol. 32, no. 1, pp. 77-82, 1993.

[4] S. P. Aggarwal and C. K. Jaggi, "Ordering policies of deteriorating items under permissible delay in payment," Journal of the Operational Research Society, vol. 46, no. 5, pp. 658-662, 1995.

[5] A. M. M. Jamal, B. R. Sarker, and S. Wang, "An ordering policy for deteriorating items with allowable shortage and permissible delay in payment," Journal of the Operational Research Society, vol. 48 , no. 8 , pp. 826-833, 1997.

[6] H. Hwang and S. W. Shinn, "Retailer's pricing and lot sizing policy for exponentially deteriorating products under the condition of permissible delay in payments," Computers and Operations Research, vol. 24, no. 6, pp. 539-547, 1997.

[7] K. J. Chung and Y. F. Huang, “The optimal cycle time for EPQ inventory model under permissible delay in payments," International Journal of Production Economics, vol. 84, no. 3, pp. 307318, 2003.

[8] Y. F. Huang, “Optimal retailer's ordering policies in the EOQ model under trade credit financing," Journal of Operational Research Society, vol. 54, no. 9, pp. 1011-1015, 2003.

[9] J. T. Teng and S. K. Goyal, "Optimal ordering policies for a retailer in a supply chain with up-stream and down-stream trade credits," Journal of the Operational Research Society, vol. 58, no. 9, pp. 1252-1255, 2007.
[10] C. T. Chang, J. T. Teng, and S. K. Goyal, "Inventory lot-size models under trade credits: a review," Asia-Pacific Journal of Operational Research, vol. 25, no. 1, pp. 89-112, 2008.

[11] C. H. Ho, L. Y. Ouyang, and C. H. Su, "Optimal pricing, shipment and payment policy for an integrated supplier-buyer inventory model with two-part trade credit," European Journal of Operational Research, vol. 187, no. 2, pp. 496-510, 2008.

[12] Y. F. Huang and K. H. Hsu, "An EOQ model under retailer partial trade credit policy in supply chain," International Journal of Production Economics, vol. 112, no. 2, pp. 655-664, 2008.

[13] J. J. Liao, "An EOQ model with noninstantaneous receipt and exponentially deteriorating items under two-level trade credit," International Journal of Production Economics, vol. 113, no. 2, pp. 852-861, 2008.

[14] J. T. Teng and C. T. Chang, "Optimal manufacturer's replenishment policies in the EPQ model under two levels of trade credit policy," European Journal of Operational Research, vol. 195, no. 2, pp. 358-363, 2009.

[15] Y. F. Huang, "Economic order quantity under conditionally permissible delay in payments," European Journal of Operational Research, vol. 176, no. 2, pp. 911-924, 2007.

[16] C. K. Jaggi, S. K. Goyal, and S. K. Goel, "Retailer's optimal replenishment decisions with credit-linked demand under permissible delay in payments," European Journal of Operational Research, vol. 190, no. 1, pp. 130-135, 2008.

[17] A. Thangam and R. Uthayakumar, "Two-echelon trade credit financing for perishable items in a supply chain when demand depends on both selling price and credit period," Computers and Industrial Engineering, vol. 57, no. 3, pp. 773-786, 2009.

[18] J. T. Teng, "Optimal ordering policies for a retailer who offers distinct trade credits to its good and bad credit customers," International Journal of Production Economics, vol. 119, no. 2, pp. 415-423, 2009.

[19] Y. C. Tsao, "Retailer's optimal ordering and discounting policies under advance sales discount and trade credits," Computers and Industrial Engineering, vol. 56, no. 1, pp. 208-215, 2009.

[20] L. H. Chen and F. S. Kang, "Integrated inventory models considering the two-level trade credit policy and a pricenegotiation scheme," European Journal of Operational Research, vol. 205, no. 1, pp. 47-58, 2010.

[21] L. H. Chen and F. S. Kang, "Coordination between vendor and buyer considering trade credit and items of imperfect quality," International Journal of Production Economics, vol. 123, no. 1, pp. 52-61, 2010.

[22] C. T. Chang, J. T. Teng, and M. S. Chern, "Optimal manufacturer's replenishment policies for deteriorating items in a supply chain with up-stream and down-stream trade credits," International Journal of Production Economics, vol. 127, no. 1, pp. 197202, 2010.

[23] Z. T. Balkhi, "Optimal economic ordering policy with deteriorating items under different supplier trade credits for finite horizon case," International Journal of Production Economics, vol. 133, no. 1, pp. 216-223, 2011.

[24] J. J. Liao, K. N. Huang, and K. J. Chung, "Lot-sizing decisions for deteriorating items with two warehouses under an ordersize-dependent trade credit," International Journal of Production Economics, vol. 137, no. 1, pp. 102-115, 2012.

[25] Y. C. Tsao and G. J. Sheen, "A multi-item supply chain with credit periods and weight freight cost discounts," International Journal of Production Economics, vol. 135, no. 1, pp. 106-115, 2012. 
[26] A. Thangam and R. Uthayakumar, "Two-echelon trade credit financing in a supply chain with perishable items and two different payment methods," International Journal of Operational Research, vol. 11, no. 4, pp. 365-382, 2011.

[27] A. Thangam, "Optimal price discounting and lot-sizing policies for perishable items in a supply chain under advance payment scheme and two-echelon trade credits," International Journal of Production Economics, vol. 139, no. 2, pp. 459-472, 2012.

[28] S. Gulyani, "Effects of poor transportation on lean production and industrial clustering: evidence from the Indian auto industry," World Development, vol. 29, no. 7, pp. 1157-1177, 2001.

[29] E. A. Silver, "Establishing the order quantity when the amount received is uncertain," INFOR: Information Systems and Operational Research, vol. 14, no. 1, pp. 32-39, 1976.

[30] W. Shih, "Optimal inventory policies when stock outs result from defective products," International Journal of Production Research, vol. 18, no. 6, pp. 677-686, 1980.

[31] A. H. Noori and G. Keller, "One-period order quantity strategy with uncertain match between the amount received and quantity requisitioned," INFOR: Information Systems and Operational Research, vol. 24, no. 1, pp. 1-11, 1986.

[32] M. F. Blos, M. Quaddus, H. M. Wee, and K. Watanabe, "Supply chain risk management (SCRM): a case study on the automotive and electronicindustries in Brazil," Supply Chain Management, vol. 14, no. 4, pp. 247-252, 2009.

[33] Y. C. Tsao, "Replenishment policies considering trade credit and logistics risk," Scientia Iranica, vol. 18, no. 3, pp. 753-758, 2011. 


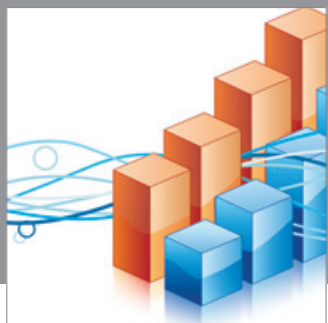

Advances in

Operations Research

mansans

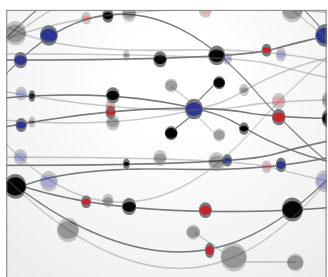

The Scientific World Journal
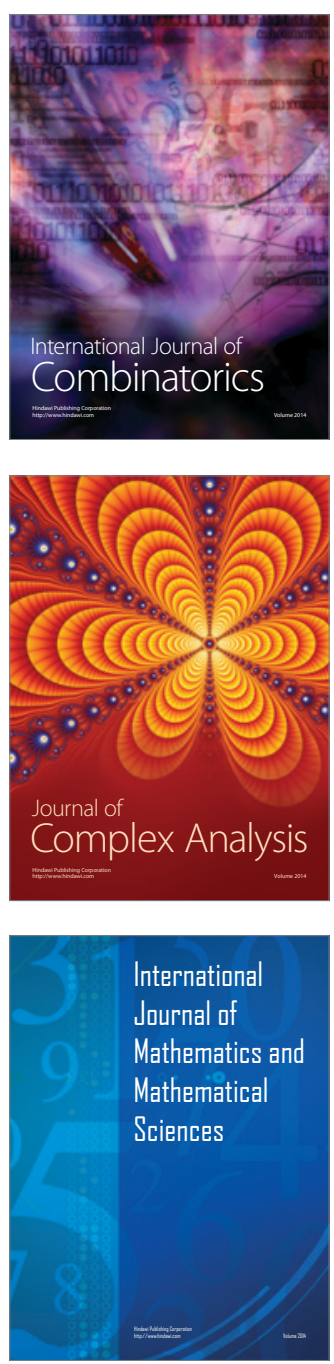
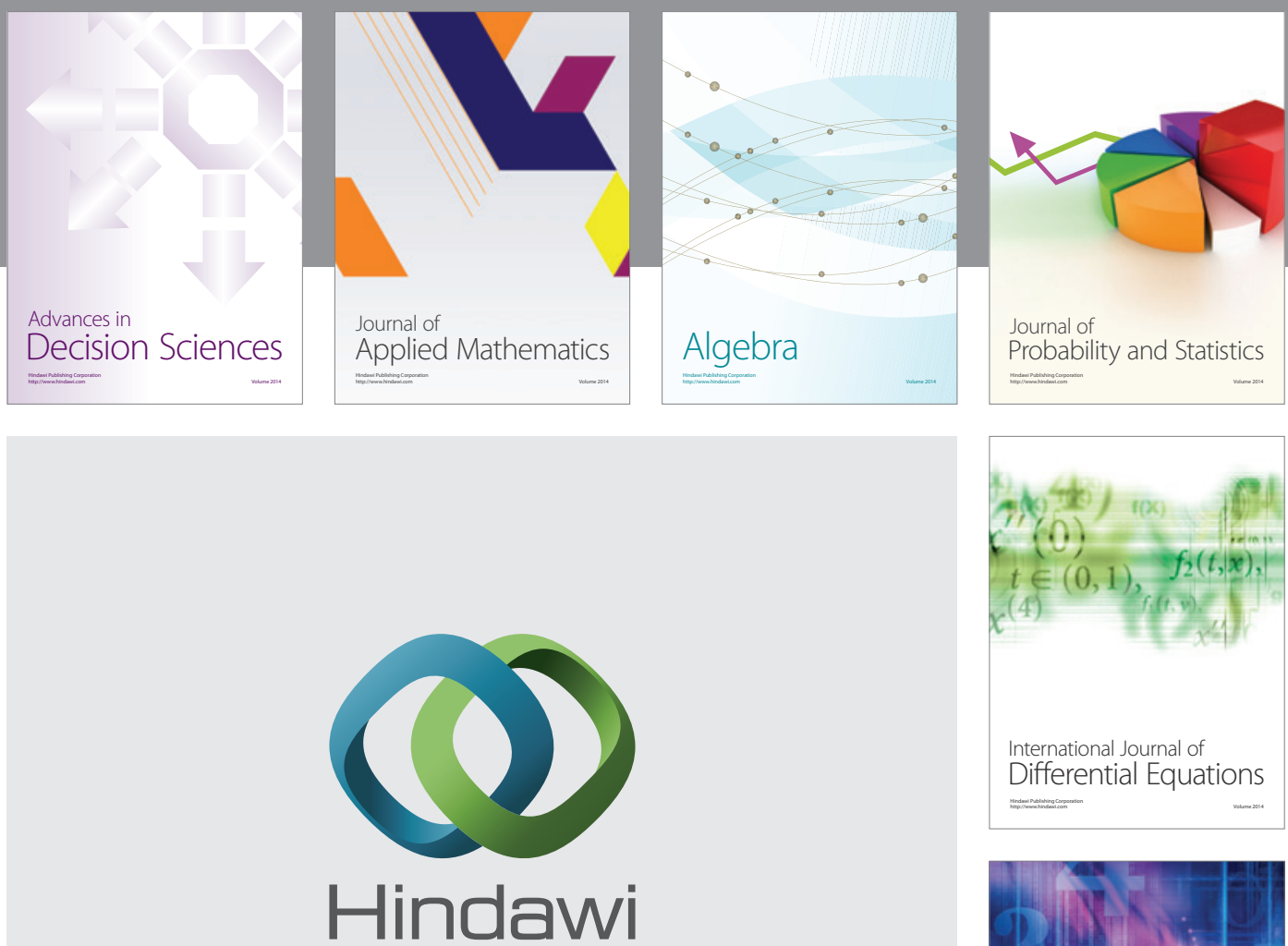

Submit your manuscripts at http://www.hindawi.com
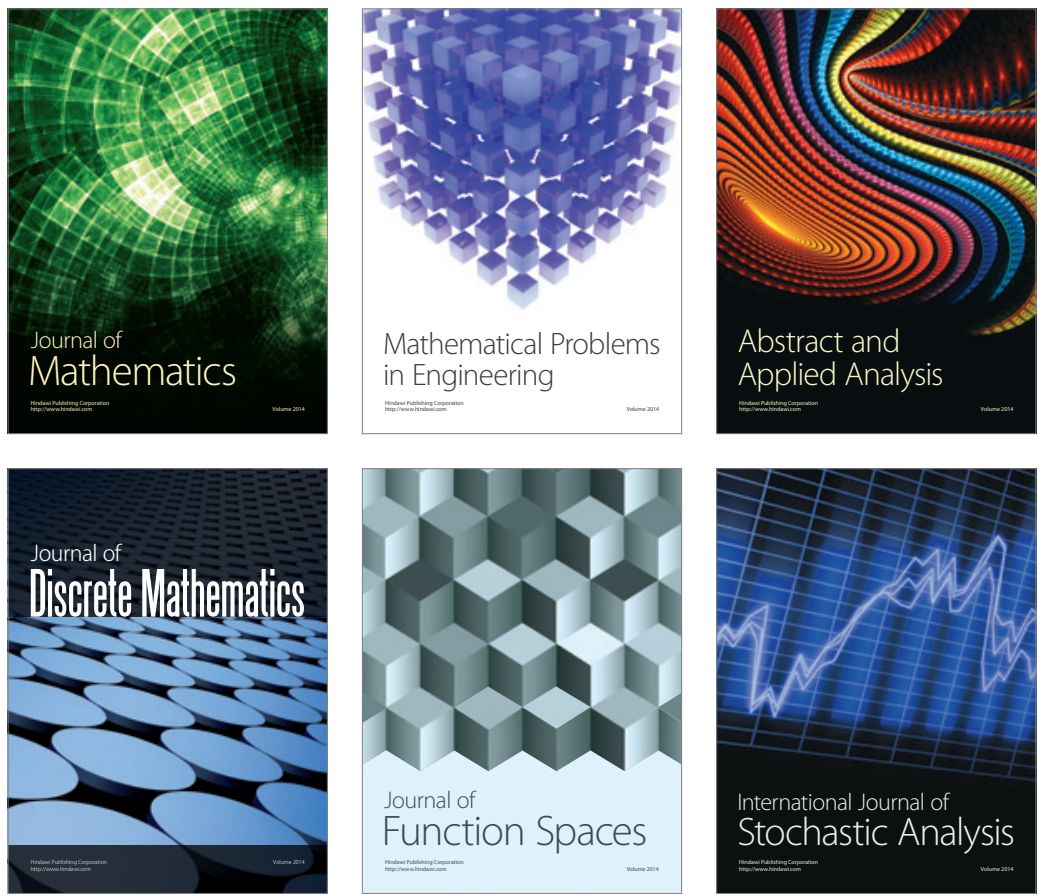

Journal of

Function Spaces

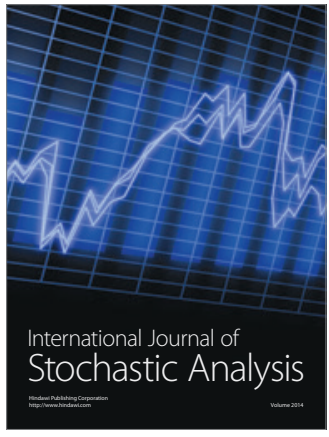

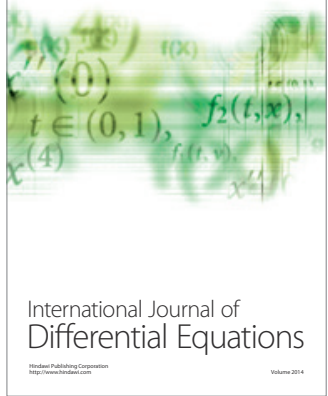
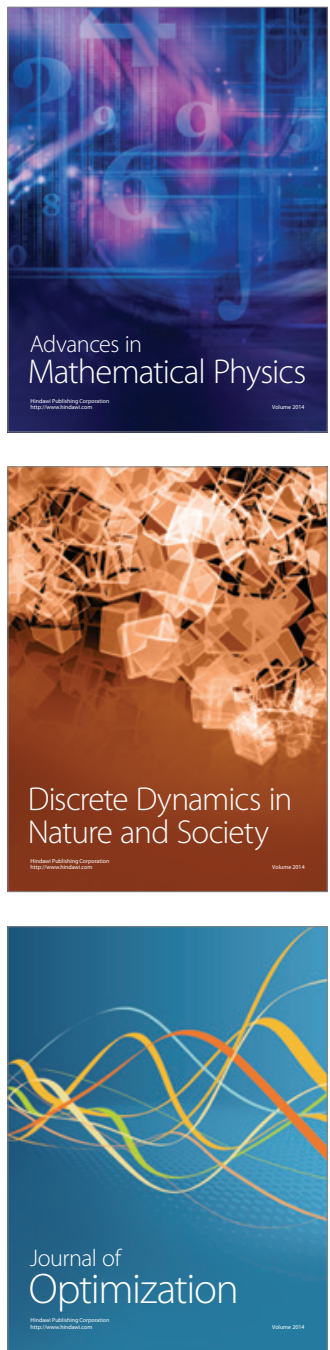